\section{Positive career shocks and career optimism: testing the mediating role of career decision-making self-efficacy}

\author{
Bilal Ahmad and Nadia Nasir \\ Department of Business and Management Sciences, Superior University, \\ Lahore, Pakistan
}

Positive career shocks and career optimism

Received 29 July 2021 Revised 3 September 2021 23 September 2021 1 October 2021 Accepted 4 October 2021

\begin{abstract}
Purpose - This study examines the relationship of positive career shocks and career optimism. The mediating role of career decision-making self-efficacy (CDSE) between positive career shocks and career optimism, and the moderating role of consideration of future consequences - immediate (CFC-I) between CDSE and career optimism is checked.

Design/methodology/approach - Through cluster sampling, cross-sectional data from 192 professionals of electronic media industry were collected via an electronically administered questionnaire. For preliminary descriptive data analysis SPSS version 21 was used. SmartPLS version 3.0 was used for testing the proposed hypotheses.

Findings - The results showed that positive career shocks have a relationship with career optimism via CDSE. Also, CFC-I moderated the relationship of CDSE and career optimism such that the relationship of CDSE and career optimism was stronger at higher level of CFC-I.

Practical implications - The study provides implications for the career consultants, human resource professionals and senior management of organizations. All these stakeholders can strive to build an inventory of positive career shocks. Also, shifting to a surprised business model of announcing compensations and promotions is another area to work on. The results of this study further suggest disengaging the fresh potential employees in the initial processes of recruitment. Interdepartmental coordination of health and safety department and human resource management department is also very important implication of this study to highlight the positive aspects of being optimistic.

Originality/value - The study is among the few empirical studies which investigates the relationship between positive career shocks and career optimism via CDSE. Also, in light of the latest call of various empirical works in the domain, this study adds a moderating variable i.e. CFC-I in predicting career optimism. Furthermore, contrary to the conventional approach of applying students' data on career models, this study tests the proposed career model on data collected from professionals.
\end{abstract}

Keywords Career shocks, Self-efficacy, Career optimism, Future consequence, Immediate consequences, Electronic media, Pakistan

Paper type Research paper

\section{Introduction}

The International Labor Organization (ILO) (2020) anticipated that by the mid-2020, roughly 200 million people will be unemployed as a result of a reduction of $7 \%$ working hours around the globe. In these circumstances, the COVID-19 pandemic added fuel to the fire. Akkermans et al. (2020) also argued that pandemics of similar nature may impact the career-related experiences and paths in short and long run. Consequently, there is a greater likelihood that individuals may encounter issues related to the development of an ideal level of optimism in

(C) Bilal Ahmad and Nadia Nasir. Published in Journal of Asian Business and Economic Studies. Published by Emerald Publishing Limited. This article is published under the Creative Commons Attribution (CC BY 4.0) licence. Anyone may reproduce, distribute, translate and create derivative works of this article (for both commercial and non-commercial purposes), subject to full attribution to the original publication and authors. The full terms of this licence may be seen at http://creativecommons. org/licences/by/4.0/legalcode

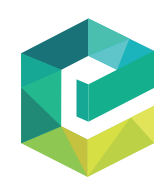

Journal of Asian Business and Economic Studies 
terms of their career such as job dissatisfaction, career indecisiveness and career stress (Eva et al., 2020). The outbreak of COVID-19 has not only undermined the future career certainty of workers but also lessened their control over their professional life (Akkermans et al., 2020). The pandemic has been a serious threat to the future success of workers across the world (Chen et al., 2020). A recent inquiry of university students showed that COVID-19 has negatively affected the students' optimism (Biber et al., 2020; Genc and Arslan, 2021). A study of healthcare workers in Turkey found that the stress of COVID-19 decreases optimism (Yildirim et al., 2021). Another study tested the sampled data collected from Latin American countries and showed that COVID-19 pandemic perception is negatively related to the optimism of individuals (Hernández-Sánchez et al., 2020), which in turn, discourages them from engaging in constructive career development processes such as entrepreneurship.

Contextualizing the matter, the Global Consumer Confidence Index (GCCI, 2020) has also reported that only $9 \%$ of the Pakistani workforce is optimistic while the rest of the population has fewer positive expectations regarding their future in terms of career. According to a latest survey report of Global Consumer Confidence Index (GCGI, 2020) almost 83\% of the employees in Pakistan are worried about their future career prospects and majority of these have concerns with regards to job security. This is a big figure which requires immediate attention because this has put very serious constraints for individuals and limited the level of optimism in the thought process of their future career prospects.

Building career optimism among employees is imperative for the organizations owing to the fact that optimism helps to: reduce the rate of employees' turnover intention (Baruch and Lavi-Steiner, 2015; Guan et al., 2015), increase the employees' performance (Young, 2018; Garcia et al., 2015), make people adjustive to their career planning strategies (Creed, 2002) and sharp their future career insight (Rottinghaus et al., 2005). Drawing on these potential benefits of building career optimism for employees, it is attributed that there is a need to investigate the possible predictors of career optimism (Hofer et al., 2020).

Subsequent to the observance of a particular career shock, individuals go into the phase of critical appraisal of their developmental process of career and change their future career aspirations accordingly (Baruch et al., 2016). Literature is evident in the fact that individuals receiving positive career shocks have been more confident in pursuing their future career prospects (Blokker et al., 2019). However, positive career shocks remain largely unaddressed in the area of career optimism. Further, in addition to the effects of negative career shocks on career optimism, Hofer et al. (2020) directed the future work to investigate the possible positive effects of positive career shocks on career optimism. Positive career shocks such as quick promotion and salary raise can be viewed as a "constructive resource" (Shin et al., 2012) - a resource type which further enables individuals to obtain another "key resource" - the self-efficacy (Chen et al., 2009). Seeing with the lens of CoR theory Hobfoll (2001) further confirms that high self-efficacy fosters optimism. In social cognitive career theory, CDSE is theorized as a mediating variable between personal factors (e.g. career shocks) and careerrelated outcomes (e.g. career optimism) (Lent et al., 1994; Penn and Lent, 2019). Personal factors explicitly shape an individual's CDSE, which further triggers them to think optimistically regarding their future career outcomes, thereby promoting career optimism. Hence, this study addresses the gap through embedding CDSE as an immediate positive outcome of positive career shocks, and as a bridging variable between the positive career shocks and career optimism.

Recent scholarships have suggested the inclusion of moderating variables while examining the relationship of career optimism with related variables of interest (Eva, et al., 2020). Advancingly, Hofer et al. (2020) have suggested incorporating the key resources (e.g. personal resources, career resources, energy resources) as moderators to check their effect on career attitudes. Chui et al. (2020) also recommended investigating the personal factors in assessing the antecedents of career optimism. Despite a call to add moderating 
variables in assessing the antecedents of career optimism, there is limited number of empirical work discussing the moderating variables on the subject of career optimism (Kim et al., 2016). Based on the recommendations of these recent studies (Hofer et al., 2020; Chui et al., 2020), this study proposes CFC-I (a key personal resource) as a moderating factor on the relationship between CDSE and career optimism. Drawing on the aforementioned theoretical gaps, this study will address the following research questions:

\section{$R Q 1$. Are positive career shocks and career optimism related?}

$R Q 2$. Does CDSE mediate the relationship of positive career shocks and career optimism?

RQ3. Does CFC-I moderate the relationship of CDSE and career optimism?

\section{Theory and hypotheses}

\subsection{Conservation of resources (CoR) theory}

CoR theory has an advantage over other competing theories owing to its ability to explain the interrelationships between various contextual and personal resources. Also, CoR theory explains the degree to which an environment is favorable or unfavorable for the creation of such resources (Hobfoll et al., 2018). Hobfoll and colleagues further elaborated that organizations and culture significantly impact the process of resource creation and also determine to nurture or limit these resources. Eva et al. (2020) recommended drawing on the $\mathrm{CoR}$ theory in order to understand the development of career optimism. They further take insight from the work of Brummelhuis and Bakker (2012) that personal resources (e.g. positive career shocks, CDSE) may help in building psychological resources (e.g. career optimism).

In the perspective of CoR theory, resources are viewed as "anything perceived by the individual to help attain his or her goals" (Halbesleben et al., 2014, p. 1338). These resources may be "objects, personal characteristics, conditions, or energies" (Hobfoll, 1989, p. 516). The chain of resource gain does not break and continues to obtain other resources (Hobfoll, 2011). Arguably, in this study's context, positive career shocks such as quick promotion and salary raise can be viewed as "constructive resource" (Shin et al., 2012) - a resource type which further enables individuals to obtain another "key resource" - the self-efficacy (Chen et al., 2009). Seeing with the lens of CoR theory, Hobfoll (2001) further confirms that high selfefficacy fosters optimism. Convincingly, CoR theory better explains the theoretical structure of the model proposed for this study, and therefore qualifies to be drawn upon.

\subsection{Positive career shocks and CDSE}

Career shock is normally characterized as "a disruptive and extraordinary event that is, at least to some degree, caused by factors outside the focal individual's control and that triggers a deliberate thought process concerning one's career" (Akkermans et al., 2018, p. 4). In terms of response, there are events which are positively received by individuals while others are not (Akkermans et al., 2018). Career decision-making self-efficacy is defined as "the domain of behaviors relevant to the process of career decision making (. . .) relevant to the career choice competencies of (1) accurate self-appraisal, (2) gathering occupational information, (3) goal selection, (4) making plans for the future, and (5) problem solving" (Taylor and Betz, 1983, p. 69). Evidently, CDSE is an important personal resource amidst the individuals' career development. Also, CoR theory sees self-efficacy as an important "key resource" (Chen et al., 2009) because self-efficacy can foster positive career-related outcomes such as employees' career commitment (Niu, 2010) and work engagement (Wang and Tseng, 2019).

Previous scholarships on the subject matter have well documented the positive linear relationship between nature of shock and eventual outcome (e.g. Hofer et al., 2020). This implies that positive career shocks are related to positive outcomes, while negative career 
shocks are related to negative outcomes (e.g. Baruch and Lavi-Steiner, 2015; Seibert et al., 2013). A sudden elevation to a senior post may be characterized as a positive career shock while a sudden departure of a colleague or mentor may be characterized as a negative career shock. Nature of shock has been one of the major determinants of individuals' capacity to achieve career related goals. Literature is evident in the fact that individuals receiving positive career shocks have been more confident in pursuing their future career prospects (Blokker et al., 2019). In contrast to the preceding argument, negative career shocks depreciate individuals' decision-making regarding their career, which eventually decreases career progress (e.g. Grimland et al., 2012; Seibert et al., 2013). Subsequent to the observance of a particular career shock, individuals go into the phase of critical appraisal of their developmental process of career and change their future career aspirations accordingly (Baruch et al., 2016). The CoR theory categorizes employee rewards such as promotion and salary increments as the "constructive resources" (Shin et al., 2012), and earning a reward informs individuals about their capability, which in turn fosters their self-efficacy (Park and Yang, 2019). Positive career shocks such as quick promotion and salary raise can be viewed as a "constructive resource" (Shin et al., 2012) - a resource type which further enables individuals to obtain another "key resource" - the self-efficacy (Chen et al., 2009). Drawing on the arguments of Blokker et al. (2019), Baruch et al. (2016), and tenets of CoR theory, it is expected that:

H1. There is a positive relationship between positive career shocks and CDSE

\subsection{CDSE and career optimism}

Social cognitive career theory (Lent et al., 1994) explicitly portrays an individual's future career expectations which are largely based on the individual's perceived capacity to perform in a certain context. Drawing on this perspective of social cognitive career theory, an individual's confidence to perform a certain action such as confidence to take career-related decisions - which is also referred to as CDSE, will lead to the positive career-related outcomes such as career optimism. Li et al. (2019) assert that individuals with higher levels of CDSE, perceive less barriers to their career path. Eventually, they tend to engage in career exploration activities with a positive frame of mind. Chui et al. (2020) further argued that individuals' involvement in career-related exploration activities may eventually make them able to believe and expect positive future career outcomes. Urbig and Monsen (2012) found a positive relationship between general self-efficacy and optimism. Chatterjee et al. (2015) also argued that career self-efficacy and optimism are positively related. Recently, Aymans et al. (2020) found a relationship between self-efficacy and optimism. Beside these theoretical supports to the relationship of general self-efficacy and optimism, there is evidence in literature to support the relationship of CDSE and career optimism (e.g. Eva et al., 2020; McLennan et al., 2017; Garcia et al., 2015). Drawing on these evidences, it is hypothesized that:

H2. There is a positive relationship between CDSE and career optimism.

\subsection{Mediating role of CDSE}

Subsequent to the observance of a particular career shock, individuals go into the phase of critical appraisal of their developmental process of career and change their future career aspirations accordingly (Baruch et al., 2016). For example, an individual's success in a challenging and seemingly impossible professional assignment, develops a positive perception regarding career progress (Hall, 2002). This scenario further explains that an individual's strategies related to career are working and there is more likelihood that the individual will be able to decide to proceed with the current approach (Sibert et al., 2013). It is argued that since positive career shocks do not violate the current career image and positively 
impact the decision-making (Sibert et al., 2013) therefore individuals experiencing positive career shocks are more likely to hold an optimistic view of their career in future.

Higher self-efficacy enables individuals to boost their optimism level in a given domain (Maddux, 2002). Social cognitive career theory confirms that individuals rely on their own capabilities in the course of career development (Ho and Sum, 2018). CDSE refers to "an individual's degree of belief that he or she can successfully complete tasks necessary to making career decisions" (Betz et al., 1996, p. 48). The ability to make a career choice and perform in a certain career domain, both explain CDSE (Lent et al., 1994). CDSE enables individuals to apply appropriate relevant skills to their career, face adversity from the front, and continuously explore career opportunities (Penn and Lent, 2019). Previous studies have reported that CDSE is related to several vocational outcomes such as career commitment, career decidedness and occupational aspirations (Rogers and Creed, 2011; Chung, 2002). Several recent studies have found a positive relationship between CDSE and career optimism (e.g. Eva et al., 2020; McLennan et al., 2017; Garcia et al., 2015).

Positive career shocks such as quick promotion and salary raise can be viewed as a "constructive resource" (Shin et al., 2012) - a resource type which further enables individuals to obtain another "key resource" - the self-efficacy (Chen et al., 2009). Seeing with the lens of CoR theory Hobfoll (2001) further confirms that high self-efficacy fosters optimism. In social cognitive career theory, CDSE is theorized as a mediating variable between personal factors (e.g. career shocks) and career-related outcomes (e.g. career optimism) (Lent et al., 1994; Penn and Lent, 2019). Personal factors explicitly shape an individual's CDSE, which further triggers them to think optimistically regarding their future career outcomes, thereby promoting career optimism. Thus, it is hypothesized that:

H3. CDSE mediates the relationship of positive career shocks and career optimism.

\subsection{Moderating role of CFC-I}

The consideration of future consequences is defined as "the extent to which individuals consider the potential distant outcomes of their current behaviors and the extent to which they are influenced by these potential out-comes" (Strathman et al., 1994, p. 743). This is a cognitive-motivational variable that explains the degree to which individuals bother the expected future outcomes of their current behavior and decisions (Murphy et al., 2020). Individuals with an acute level of foresight, weigh the long term impact of their current decisions and behaviors, and accordingly demonstrate high consideration of future consequences. They strive to eliminate the possibility of the occurrence of undesirable, unpleasant and destructive events in future (e.g. Adams and Nettle, 2009; Graso and Probst, 2012). Opposingly, those with low on consideration of future consequences are less likely to account for the future outcomes of their current decisions and behaviors. Individuals with low consideration of future consequences assign more weightage to the immediate outcomes of their current decisions and behaviors (Joireman et al., 2006; Orbell and Kyriakaki, 2008).

Available literature on the subject matter is evident that personality variables such as consideration of future consequences determine a number of individual behaviors like job performance (Graso and Probst, 2012), alcohol use (Strathman et al., 1994) and self-control (Joireman et al., 2006). Construal level theory (CLT) - a social psychology theory (Liberman and Trope, 1998) is used to explain the moderating effect of the CFC-I on the relationship between CDSE and career optimism. The CLT has been used to understand the individuals' decisions in the area of psychology (e.g. Fujita and Sasota, 2011). Construal means how people understand and interpret the world around them. CLT confirms that the degree to which a particular event, task, or object is psychologically distant, impacts the level these are being construed by individuals. Hypotheticality is one of the determinants of psychological distance (Trope and Liberman, 2010). As per CLT, individuals confronting the

\section{Positive career shocks and career optimism}


psychologically "near event" are able to understand and interpret that event in a clear and concrete manner, often referred to as low construal level. Hence, CFC-I may be treated as having low construal level. It has been evidenced that individuals' understanding and interpretation of worldly events i.e. the way individuals construe those events, impacts their decision making and evaluation (c.f. Kim et al., 2016). Also, Alfalah and Alganem (2020) argued that both low and high levels of construal, if skillfully used, may impact the positive psychological factors such as optimism (see Figure 1).

CDSE shows individuals' perceived ability and confidence in making their career-related decisions. Individuals having high CDSE are more likely to make better decisions as compared to their counterparts who show low CDSE. Since decision-making, in one way or another, predicts well-being of people; therefore, consequences of being low or high at CDSE makes individuals think about their current decision-making ability. It is therefore logical to argue that the time perspective influences the decision-making and the associated outcome with that particular decision. Hence, when people believe that their inability to make careerrelated decisions will lead to negative career consequences in future such as low career optimism (or even high pessimism related to career goals), they are less likely to engage in such activities which may undermine their CDSE level. Drawing on these arguments, it is expected that:

H4. The relationship between CDSE and career optimism is moderated by CFC-I, such that the relationship is stronger with increasing levels of CFC-I.

\section{Methodology}

Based on the existing theories and literature, this study develops a hypothetical relationship among the variables of interest. These hypothetical relationships are further tested on the data collected from the participants. Therefore, a quantitative research approach is more appropriate for this study (Saunders et al., 2016). Furthermore, since this study intends to generalize the findings; thus, deduction is the more appropriate technique to rely on (Saunders et al., 2016). Another reason for employing the quantitative methodology is that the maximum risk associated with the quantitative methodology is the non-return of survey questionnaires from some of the respondents. However, in qualitative inquiries one may

Figure 1.

Proposed theoretical framework

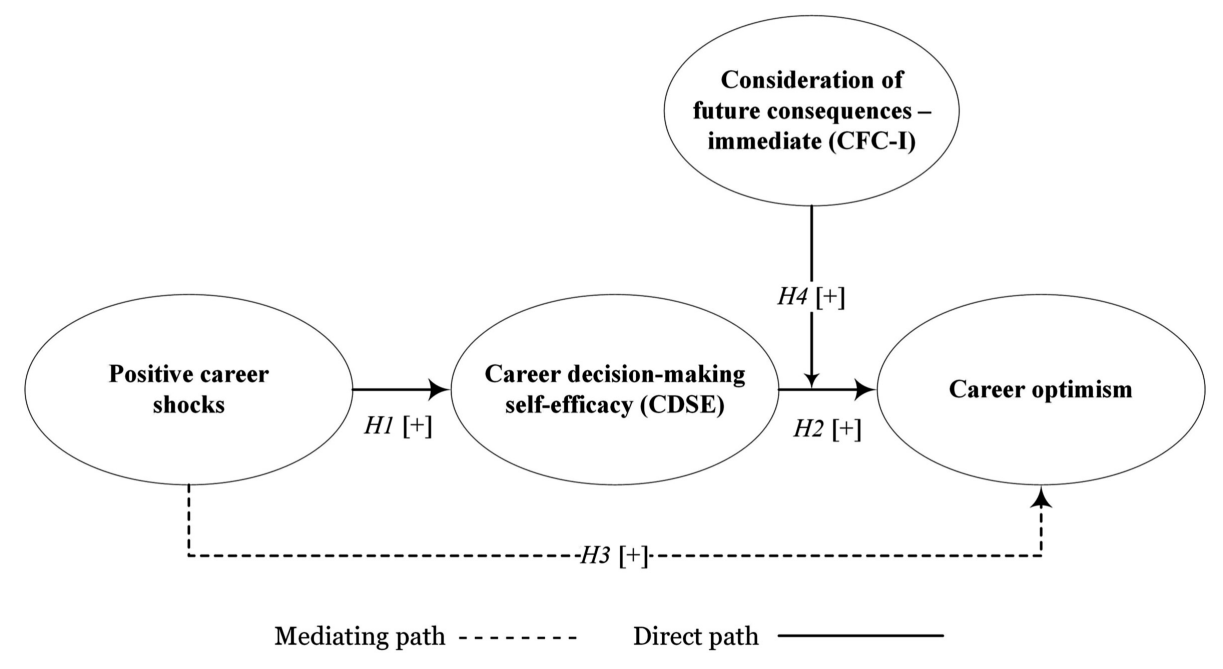


encounter the problem of not being able to draw meaningful information out of the available evidence (Cooper and Schindler, 2003).

\subsection{Measures}

Two items of career shock, related to the "visible job success" and "quick raise or promotion", were adopted from Sibert et al. (2013) and one item (i.e. "after completing your education, you found your first job faster than expected") was adopted from Blokker et al. (2019), anchored on a five-point Likert scale numbered 0 for "no impact at all or never experience the shock" and 4 indicative of the "had a large impact." These three items have also been used in previous studies (Blokker et al., 2019). A count variable was created to calculate the aggregated score against the three items of positive career shocks. Owing to the stated nature of variable (positive career shocks), reliability statistics were not obtained (e.g. Blokker et al., 2019).

To measure CDSE, a short form of CDSE scale was used (Betz et al., 1996). Anchored on a five-point Likert scale ranging from 1 = "no confidence at all" to $5=$ "complete confidence", it is a five dimensional scale having five items of each dimension (a second-order reflective construct). Problem solving (e.g. "change majors if you did not like your first choice"), goal selection (e.g. "make a career decision and then not worry if it was right or wrong"), selfappraisal (e.g. "figure out what you are and are not ready to sacrifice for your career goals"), occupational information (e.g. "find information about graduate or professional schools"), planning (e.g. "successfully manage the job interview process") each were measured with five items. The construct has extensively been deployed in previous research and has been found extremely reliable (e.g. Dik et al., 2008; $\alpha=0.92$ ). Item parceling was conducted on CDSE scale owing to a larger number of dimensions and associated items (Little $e$ t al., 2002). As defined by Matsunaga (2008) parceling is the process of "aggregating items and using those aggregates as indicators of latent constructs, for structural equation modeling (SEM)." Previous studies have also deployed the parceling technique particularly of CDSE scale (e.g. Doo and Park, 2019). Of the 25 items of CDSE scale, 5 parcels namely problem-solving, goal selection, selfappraisal, occupational information and planning were formed and treated as indicators of CDSE (Little et al., 2002; Doo and Park, 2019).

Career optimism was measured with an 11-item scale anchored on a five-point Likert scale ranging from $1=$ "strongly disagree" to $5=$ "strongly agree" (Rottinghaus et al., 2005). A sample item includes "I get excited when I think about my career". The scale has shown good reliability in previous studies (e.g. Chui et al., 2020; $\alpha=0.85$ ). This is a first-order reflective construct.

CFC-I was measured with a seven-item scale (Joireman et al., 2012). Anchored with a fivepoint Likert scale ranging from $1=$ "strongly disagree" to $5=$ "strongly agree", the scale has shown good reliability in previous studies (e.g. Joireman et al., 2012; $\alpha=0.84$ ). A sample item includes "I only act to satisfy immediate concerns, figuring the future will take care of itself." This is a first-order reflective construct.

\subsection{Sampling and data collection}

Data for this study were taken from employees (entry level to management level having minimum six months of experience) of the electronic media (television channels) in Pakistan. According to the latest statistics available with the Pakistan Electronic Media and Regulatory Authority (PEMRA), licenses to 110 television channels have been issued in different categories such as entertainment, education and religion. Of these 110 television channels, $43 \%$ are located in Karachi - the largest city of Pakistan. Thus, two clusters namely "Karachi" and "other than Karachi" were formed to collect the data.

Statistics regarding working employees in the electronic media industry are not available. Therefore, it was not possible to determine the exact count of population and sample to be
Positive career shocks and career

optimism 
drawn. Hence, this study employed $\mathrm{G}^{*}$ Power technique to estimate the required sample size because it has been a priority of researchers in the field of social sciences (Hair et al., 2017). Evidently, the sample used for this study (192) is fairly higher than the recommended sample size (176) by G*Power. According to Uttley (2019), 80\% power value is adequate for social science research. Further, the study obtained actual power $=0.95, \alpha=0.05$, and effect size $=0.15$ against the recommended sample size of 176 .

A list of 6,734 employees (both clusters inclusive) working in any category of television channel was compiled. Owing to the present situation of COVID-19 and to comply with the State order of maintaining the social distance, the questionnaire was electronically administered to the 1,000 randomly selected employees. Also, this technique serves well to minimize the degree of social desirability bias (Heerwegh, 2009). This participation was voluntary and all questions were kept non-mandatory i.e. participants may skip the questions they do not want to respond. After three fortnightly follow-ups through resharing the link to the questionnaire, 667 responses were received. Of these, $192(28 \%)$ completed the questionnaire. Demographic detail of the respondents is given in Table 1.

\subsection{Treatment of missing values}

According to Little (1988) "missing data are a pervasive problem in sample surveys" (p. 287). Treatment of missing values has been a challenge for research in the field of social sciences (Rezaei et al., 2016). Among various methodologies to fix the issue of missing values, imputation has been a priority of researchers (Rezaei and Ghodsi, 2014). Imputation methodology (Rubin, 1987) is "a simulation technique that replaces each missing datum with a set of complete data $>1$ plausible values" (Schafer and Olsen, 1998, p. 545). For the

\begin{tabular}{llcc}
\hline Variable & Category & Frequency & Percentage \\
\hline \multirow{2}{*}{ Gender } & Male & 132 & $69 \%$ \\
Age & Female & 60 & $31 \%$ \\
& $20-30$ years & 36 & $19 \%$ \\
& $31-40$ years & 102 & $53 \%$ \\
Education level & 41-50 years & 44 & $23 \%$ \\
& Above 50 years & 10 & $5 \%$ \\
& College diploma/certificate & 55 & $29 \%$ \\
Professional experience & Undergraduate degree & 65 & $34 \%$ \\
& Postgraduate degree & 72 & $38 \%$ \\
& Less than a year & 13 & $7 \%$ \\
& $1-3$ years & 24 & $13 \%$ \\
Current position & 4-6 years & 102 & $53 \%$ \\
& $7-9$ years & 43 & $22 \%$ \\
& 10 years and above & 10 & $5 \%$ \\
& Entry level & 20 & $10 \%$ \\
& Individual contributor & 67 & $35 \%$ \\
Length of service (with current employer) & Manager & 60 & $31 \%$ \\
& Director & 35 & $18 \%$ \\
& Vice president & 10 & $5 \%$ \\
& Less than a year & 38 & $20 \%$ \\
& $1-2$ years & 40 & $21 \%$ \\
& 3-4 years & 95 & $49 \%$ \\
Note(s): $n=192$ & 5-6 years & 12 & $6 \%$ \\
& $7-8$ years & 6 & $3 \%$ \\
& More than 8 years & 1 & $1 \%$ \\
& & & \\
\hline
\end{tabular}

Table 1.

Demographic summary of participants

Note(s): $n=192$ 
imputation of missing values, the study used Little's (1988) algorithm of expectation maximization in SPSS. The results show that missing values in our data are at random $\left(\chi^{2}=366.38\right.$, df $\left.=435, p=0.933\right)$.

\subsection{Common method variance (CMV) and nonresponse bias}

Studies collecting data through surveys usually encounter CMV (Schwarz et al., 2017). Also, Hair et al. (2014) cautioned that a single-sourced data may bring covariances among the measured items. Hence, the study complied the guidelines of Reio (2010) and Schwarz et al. (2017) through our procedural and statistical choice to minimize the degree of CMV. Through procedural control the questionnaire was pilot tested to assess the understandability of the participants. Guidelines via a separate document were provided to the participants regarding completion of the questionnaire. Further, the participants were assured regarding secrecy and confidentiality of their information (e.g. Hai et al., 2020). Through statistical control, Harman's (1967) single-factor technique was used to examine the presence of CMV. Data were entered in SPSS version 21.0 to perform the exploratory factor analysis (EFA) to detect the existence of CMV. Items of all constructs were loaded on a single latent construct (Roni, 2014). Harman (1967) asserted that if a single factor explains more than $50 \%$ variance in EFA, the presence of CMV is confirmed. However, for the current study, our data showed $38.7 \%$ variance explained by the one latent construct. Hence, it is confirmed that CMV is not an issue in this study. Further, as a complimentary analysis, the study also reported the variance inflation factor (VIF) values to support the Harman's (1967) proposed strategy of assessing the CMV. Evidently, all VIF values were below the suggested maximum value i.e. 5 (Ringle et al., 2015). Both of our controls i.e. procedural and statistical, confirmed that there is no issue of CMV in our data.

Lewis et al. (2013) defined nonresponse bias as "a systematic and significant difference between those who respond to a survey and those who do not in terms of characteristics central to the research focus" (pp. 240-241). The study employed wave analysis to assess the nonresponse bias. Responses received earlier i.e. at the start of data collection process, were classified as the "early respondents" while the responses received at the end of the data collection process were classified as the "late respondents". Through an independent sample $t$-test we found no significant differences between the "early respondents" and "late respondents" confirming the absence of nonresponse bias.

\subsection{Structural equation modelling}

The study used partial least square structural equation modeling technique (PLS-SEM) to statistically examine the parametric aspects of the proposed model (measurement model evaluation) and hypotheses (structural model evaluation). Henseler (2010) and Chin (2010) also proposed a two-stage technique of model evaluation i.e. measurement model evaluation trailed by the structural model evaluation. The study employed PLS-SEM technique for several reasons; first, it has been preferably used in studies assessing the career-related outcomes such as career success and career optimism (e.g. Ahmad et al., 2019; Chui et al., 2020). Second, this study forecasts the relevant dependent variable (Roldan and Franco, 2012) and third, owing to the presence of a third variable between the independent variable and dependent variable (i.e. CDSE as a mediator between positive career shocks and career optimism) (cf. Memon et al., 2017). Fourth, PLS-SEM has flexibility in terms of sample size requirement and data normality.

\section{Results}

\subsection{Measurement model evaluation}

Descriptive statistics such as mean, standard deviation (SD), and correlation are reported in Table 2. Results showed that all variables are significantly correlated. Comparatively, a

\section{Positive career shocks and career optimism}


moderate level of correlation was found between PCS and CO $(r=0.65, p<0.01)$ and CDSE and $\mathrm{CO}(r=0.55, p<0.01)$. Evidently, the moderator (CFC-I) was weakly correlated with the other variables (PCS: $r=0.19$, CDSE: $r=0.32$, CO: $r=0.29 ; p<0.01$ ).

Research on reporting the critical threshold values of model fit in PLS-SEM is still underway; and therefore researchers should report fit indices with caution because these may not actually reflect the model fit (Hair et al., 2017). There is evidence of not reporting model fit indices in studies employing PLS-SEM as a tool of analyses (e.g. Rubel et al., 2021). Further, fit measures often require compliance to the residual covariance assumptions (Lohmoller, 1989) while PLS-SEM does not calculate covariances in the process of model estimation. Nevertheless, the study reported SRMR value (0.07) as a measure of model fit (Henseler et al., 2014). Conservatively, a value up to 0.10 or preferably below is considered a good fit (Hu and Bentler, 1999).

The study tested internal reliability, convergent validity (CV) and discriminant validity (DV) through the measurement model evaluation. For internal reliability we calculated the composite reliability (CR) score (Hair et al., 2017). The recommended value for CR is 0.7 at minimum (Richter et al., 2012). The results obtained for the measurement model evaluation show that value of CR is well above the threshold value (0.70) - CDSE (0.86), career optimism (0.93) and CFC-I (0.95) - thereby confirming the constructs of the study have an adequate level of internal consistency (See Table 3).

The study measured CV through outer loadings of the items of constructs and average variance extracted (AVE). A value of 0.7 or above is considered acceptable for outer loadings; and for AVE, a value of 0.5 is acceptable (Avkiran, 2017). However, Chin et al. (1997) suggested a value up to 0.6 is also acceptable. In respect of factor loadings, Hair et al. (2017) explained that indicators with weaker loadings can also be considered as good if the items with higher outer loadings can explain $50 \%$ of the variance (AVE $=0.50)$. All constructs' items had outer loadings above 0.7 except three items (e.g. "It is difficult for me to set career goals") of career optimism and one item of CFC-I ("I only act to satisfy immediate concerns, figuring that I will take care of future problems that may occur at a later date"), which were deleted subsequently because of having higher similarity with other items (e.g. Chui et al., 2020). All constructs also complied the recommended threshold value of AVE i.e. 0.5 (Avkiran, 2017) - CDSE (0.56), career optimism (0.62) and CFC-I (0.78) - thereby confirming the convergent validity of the constructs (see Table 3).

Some recent studies have reported that Fornell and Larcker's (1981) technique does not assess the DV in an appropriate manner in most of the research situations (e.g. Pahi et al., 2020; Henseler et al., 2015). The study employed both Heterotrait-Monotrait (HTMT) and Fornell and Larker (1981) criterion to assess the DV. Hair et al. (2017) cautioned that a value of HTMT above 0.9 is an indication of the complete similarity among the variables in a model. Our results (see Table 4) showed an adequate value of DV i.e. HTMT <0.9. Conclusively, our model confirms adequacy of the measurement model in terms of internal reliability, CV and DV (see Tables 3 and 4).

\begin{tabular}{lccclll}
\hline Variable & Mean & SD & PCS & CDSE & CO & CFC-I \\
\hline PCS & 4.25 & 0.77 & 1 & $0.45^{* *}$ & $0.65^{* *}$ & $0.19^{* *}$ \\
CDSE & 3.94 & 0.58 & & 1 & $0.55^{* *}$ & $0.32^{* *}$ \\
CO & 3.99 & 0.68 & & & 1 & $0.29^{* *}$ \\
CFC-I & 3.90 & 0.70 & & & & 1
\end{tabular}

Table 2.

Descriptive statistics

Note(s): PCS = Positive career shocks, $\mathrm{CO}=$ Career optimism, CDSE $=$ Career decision-making selfefficacy, CFC-I $=$ Consideration of future consequences - immediate, ${ }^{* *}$ correlation is significant at the 0.01 level (2-tailed) 


\begin{tabular}{|c|c|c|c|c|c|c|}
\hline Construct & Loading & VIF & $\alpha$ & $\mathrm{CR}^{\mathrm{a}}$ & $\mathrm{AVE}^{\mathrm{b}}$ & Positive career \\
\hline Career decision-making self-efficacy (CDSE) & & & 0.80 & 0.86 & 0.56 & career \\
\hline CDSE 1 & 0.797 & 1.716 & & & & antimism \\
\hline CDSE 2 & 0.718 & 1.756 & & & & \\
\hline CDSE 3 & 0.780 & 1.794 & & & & \\
\hline CDSE 4 & 0.876 & 2.466 & & & & \\
\hline CDSE 5 & 0.532 & 1.279 & & & & \\
\hline Career optimism (CO) & & & 0.91 & 0.93 & 0.62 & \\
\hline CO 1 & 0.609 & 2.124 & & & & \\
\hline $\mathrm{CO} 2$ & 0.814 & 2.489 & & & & \\
\hline $\mathrm{CO} 3$ & 0.823 & 2.547 & & & & \\
\hline $\mathrm{CO} 4$ & 0.790 & 2.407 & & & & \\
\hline CO 5 (deleted) & - & - & & & & \\
\hline CO 6 & 0.812 & 2.783 & & & & \\
\hline CO 7 & 0.788 & 2.219 & & & & \\
\hline CO 8 (deleted) & - & - & & & & \\
\hline CO 9 (deleted) & - & - & & & & \\
\hline CO 10 & 0.872 & 3.035 & & & & \\
\hline CO 11 & 0.814 & 2.464 & & & & \\
\hline Consideration of future consequences - immediate (CFC-I) & & & 0.94 & 0.95 & 0.78 & \\
\hline CFC-I 1 & 0.885 & 2.288 & & & & \\
\hline CFC-I 2 & 0.882 & 3.072 & & & & \\
\hline CFC-I 3 & 0.924 & 2.412 & & & & \\
\hline CFC-I 4 & 0.893 & 3.074 & & & & \\
\hline CFC-I 5 & 0.851 & 2.725 & & & & \\
\hline CFC-I 6 (deleted) & - & - & & & & \\
\hline CFC-I 7 & 0.869 & 2.755 & & & & \\
\hline
\end{tabular}


the factor loadings) + (square of the summation of the error variance) $] ;^{\mathrm{b}} \mathrm{AVE}=($ Summation of squared factor loadings)/(Summation of squared factor loadings) (Summation of error variances); $\alpha=$ Cronbach's alpha

Table 3.

Validity and reliability of constructs

\begin{tabular}{|c|c|c|c|c|c|c|c|c|}
\hline \multicolumn{4}{|c|}{ Fornell-Larcker criterion } & \multicolumn{4}{|c|}{ HTMT } & \\
\hline & 1 & 2 & 3 & 4 & 1 & 2 & 3 & \\
\hline 1. CDSE & 0.750 & & & & & & & \\
\hline 2. CFC-I & 0.346 & 0.884 & & & 0.374 & & & \\
\hline 3. $\mathrm{CO}$ & 0.593 & 0.300 & 0.794 & & 0.643 & 0.312 & & \\
\hline 4. PCS & 0.499 & 0.203 & 0.693 & 0.840 & 0.563 & 0.228 & 0.775 & \\
\hline \multicolumn{8}{|c|}{$\begin{array}{l}\text { Note(s): } \mathrm{PCS}=\text { Positive career shocks, } \mathrm{CO}=\text { Career optimism, } \mathrm{CDSE}=\text { Career decision-making self-efficacy, } \\
\text { CFC-I = Consideration of future consequences - immediate }\end{array}$} & $\begin{array}{r}\text { Discriminant validity } \\
\text { of constructs }\end{array}$ \\
\hline
\end{tabular}

\subsection{Structural model evaluation}

The potential issue of collinearity was examined prior to the evaluation of the structural model. A value of variance inflation factor (VIF) greater than 10 is an indication of the presence of multicollinearity. The study obtained a value of VIF below 5.0 for all the constructs in our model, ranging from 1 to 3 , thereby confirming that collinearity is not an issue in our case.

The study applied bootstrapping technique with 5,000 resample to assess the significance of our proposed model (Hair et al., 2017). Results of hypotheses testing are reported in Table 5 and have also been shown in Figure 2. The study found a positive relationship between positive career shocks and CDSE (H1: $\beta=0.49, p<0.05)$. Thus, $\mathrm{H} 1$ was accepted as proposed. 
This implies that employees receiving positive career shocks such as quick promotion or unexpected salary rise are positively related to their decision-making of career-related prospects. Positive career shocks are likely to supplement confidence to individuals in making their career-related decisions. The relationship of CDSE and career optimism was also substantiated (H2: $\beta=0.26, p<0.05)$. Thus, $\mathrm{H} 2$ was accepted as proposed. This has been supported in previous studies as well (e.g. Chui et al., 2020; Garcia et al., 2015). This finding shows that individuals' increased ability and confidence of making their career-related decisions are the enablers of their positive expectations of career in future.

Latest guidelines on quantitative methodologies suggest treating the direct or total effects as least important while analyzing the mediating models (Hayes and Rockwood, 2016; Rucker et al., 2011). Therefore, the study also examined the indirect effects i.e. the mediating role of CDSE on the relationship between positive career shocks and career optimism. The results show that CDSE mediates the relationship of positive career shocks and career optimism (H3: $\beta=0.13, p<0.05)$. Thus, H3 was substantiated. Since a direct relationship between positive career shocks and career optimism was also supported; therefore, it is logical to attribute that CDSE partially mediates the relationship of positive career shocks and career optimism.

$\mathrm{H} 4$ hypothesizes that the relationship between CDSE and career optimism is moderated by CFC-I, such that the relationship is stronger with increasing levels of CFC-I. Results showed that CFC-I moderates the relationship of CDSE and career optimism (H4: $\beta=0.13, p<0.05)$. Slopes drawn in Figure 3 showed that the relationship between CDSE and career optimism is stronger at high levels of CFC-I. Hence, our results of moderation analysis uphold the

Table 5.

Results of structural model assessment

\begin{tabular}{llccccccc}
\hline Hypothesis & Path & $\beta$ & $t$-value & $R^{2}$ & $f^{2}$ & $Q^{2}$ & $p$-value & Decision \\
\hline$H 1$ & PCS $\rightarrow$ CDSE & 0.49 & 07.65 & 0.24 & 0.33 & 0.12 & 0.000 & Supported \\
H2 & CDSE $\rightarrow$ CO & 0.26 & 04.26 & 0.59 & 0.11 & 0.35 & 0.000 & Supported \\
H3 & PCS $\rightarrow$ CDSE $\rightarrow$ CO & 0.13 & 03.22 & & & & 0.001 & Supported \\
H4 & CDSE $\times$ CFC-I $\rightarrow$ CO & 0.13 & 02.01 & & & & 0.044 & Supported
\end{tabular}

Note(s): $\mathrm{PCS}=$ Positive career shocks, $\mathrm{CO}=$ Career optimism, $\mathrm{CDSE}=$ Career decision-making self-efficacy, $\mathrm{CFC}-\mathrm{I}=$ Consideration of future consequences - immediate

Figure 2 .

Results of structural model assessment

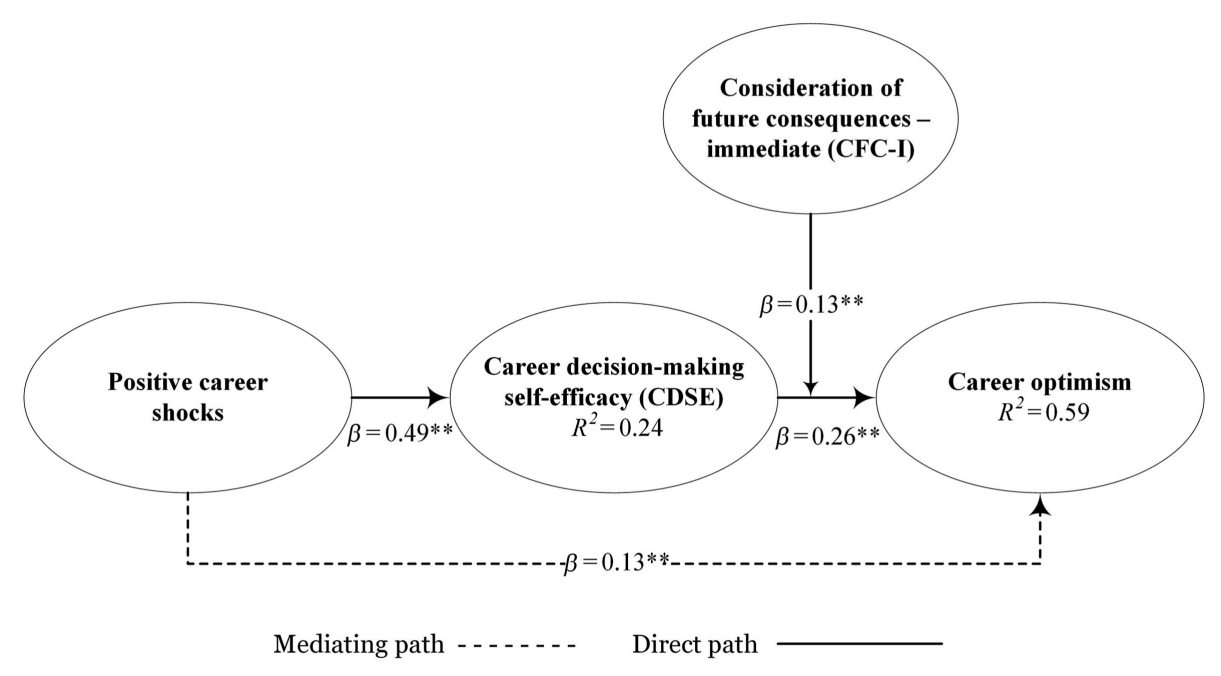






Positive career shocks and career optimism

Figure 3. Moderating role of CFC-I between CDSE and career optimism

assertion that the interaction between CDSE and CFC-I was positively related to career optimism.

There is theoretical evidence of performing the additional analyses such as coefficient of determination $\left(R^{2}\right)$, effect sizes $\left(f^{2}\right)$ and predictive relevance $\left(Q^{2}\right)$ in studies involving careerrelated models (e.g. Ahmad et al., 2019). Also, Hair et al. (2017) recommended and provided guidelines to perform these analyses. Arguably, the degree to which a predictor variable explains variance in the other endogenous variable, is determined by $R^{2}$. Results in Table 5 show that positive career shocks explain a reasonable variance in $\operatorname{CDSE}\left(R^{2}=0.24\right)$. Further, CDSE also explains a reasonable variance in career optimism $\left(R^{2}=0.59\right)$. The degree to which the value of $R^{2}$ of an endogenous variable is changed upon removal of its corresponding exogenous or predictor variable, is named as effect size $\left(f^{2}\right)$. Cohen (1988) bifurcated the effect size values as $0.02,0.15$ and 0.35 showing the small, medium and large effect respectively. Table 5 shows that both positive career shocks on CDSE $\left(f^{2}=0.33\right)$ and CDSE on career optimism $\left(f^{2}=0.11\right)$ have large and medium effect size respectively. Hair et al. (2014) stated that " $Q$ " values larger than zero for a certain reflective endogenous latent variable indicate the path model's predictive relevance for the particular construct" (p. 178). Our results (see Table 5) showed adequate predictive relevance of positive career shocks on $\operatorname{CDSE}\left(Q^{2}=0.12\right)$ and career optimism $\left(Q^{2}=0.35\right)$.

Considering the possible influence of demographic variables on individuals' degree of career optimism (Gunkel et al., 2013; Gunkel and Schlaegel, 2010), the study controlled the participants' gender, age, education, professional experience and position. However, results suggest that none of the demographic variables significantly impacted the career optimism (gender: $t=0.80, p>0.05$; age: $t=0.05, p>0.05$; education: $t=0.23, p>0.05$; experience: $t=0.72, p>0.05$; position: $t=1.13, p>0.05$ ).

\section{Discussion}

This study was aimed to investigate the role of positive career shocks in achieving an optimal level of career optimism through CDSE among employees of the electronic media industry in Pakistan. Drawing on the CoR theory (Hobfoll, 1989) and Construal Level Theory (Liberman and Trope, 1998), all of our proposed hypotheses were supported. On the career pathway, 
individuals are often encountered with unexpected positive career-related outcomes such as receiving a quick promotion. Convincingly, such unexpected events signaling individuals' achievements build confidence to achieve the up-hilled career milestones. Eventually, this confidence or self-efficacy further enables employees to expect the other attainable careerrelated opportunities ahead. This state of being positive regarding future career opportunities and their attainment thereof, fosters career optimism. Additionally, decisions and actions of people are either regulated or not regulated by the associated consequences. That's why, arguably, the consideration of future consequences regulate the interplay of individuals' decisions and the associated consequences of those decisions. Therefore, people who are much concerned with the future consequences are likely to engage only in such decisions which may bring positive outcomes in future. Discussed next are the theoretical and practical implications of the study.

\subsection{Theoretical implications}

This study makes novel contributions to the existing knowledge on career optimism and career shocks. First, this study was intended to answer the call of inclusion and studying the moderating variables of personal nature (CFC-I) in future models of antecedents of career optimism (e.g. Eva et al., 2020; Hofer et al., 2020; Chui et al., 2020). Our findings showed that the interplay of CDSE and career optimism gets stronger at higher levels of individuals' considerations of immediate outcomes of their current behavior. This study explicitly demonstrated how CDSE and CFC-I together enhance individuals' career optimism.

Second, in response to the call to study positive career shocks as a predictor of career optimism (e.g. Hofer et al., 2020) and unlike the previous studies that remained focused on examining the non-career related predictors of career optimism such as emotions (Chatterjee et al., 2015) and support (Chatterjee et al., 2015) etc., this research has extended the existing framework of career optimism through investigating the career-related antecedent of career optimism. For example, Hofer et al. (2020) argued that negative career shocks impact individuals' CDSE, which in turn impacts their career optimism. Our study, with the lens CoR theory explicitly demonstrated that positive career shocks play an important role in building CDSE and career optimism.

Third, previous scholarships have studied CDSE as a mediating mechanism between the personal level enablers of career optimism and career optimism itself (e.g. Garcia et al., 2015; Chui et al., 2020). This study drew on the CoR theory to broaden our understanding of the organizational and personal level enablers of career optimism via CDSE. The results of this study suggest that positive career shocks, stemming both from the personal and organizational sources, foster employees' confidence in taking career-related decisions, which in turn make them able to expect the best possible outcome in future - related to their career prospects. These findings support the assertion of the CoR theory that positive career shocks such as quick promotion and salary raise can be viewed as "constructive resources" (Shin et al., 2012) - a resource type which further enables individuals to obtain another "key resource" - the self-efficacy (Chen et al., 2009) and career optimism (Hobfoll, 2001).

\subsection{Practical implications}

This study has several practical implications for human resource managers, career consultants and management of the organizations. First, given the significant role of positive career shocks in building career optimism, organizations can follow the pattern of Blokker (2019) and Sibert (2013) in building an inventory of positive career shocks. Second, apart from the "business as usual" model of annual compensation and benefits, organizations can make surprise announcements regarding bonuses and increments on an interim basis. Third, organizations can collect graduates' credentials from the career placement cells of the universities as a part of recruitment strategy. This will keep the potential employees out of the recruitment process in 
early stages. Getting the individuals involved in the last stages of the recruitment process, and offering them jobs, can serve as a positive career shock. Fourth, Apart from the "business as usual" model of annual or mid-year performance reviews, organizations can design an "unannounced" model of employee promotions and elevations. Fifth, recently promoted and elevated employees deputed to some project, should be provided with the performance feedback on their respective projects. Those receiving positive performance reviews against projects which initially challenged them, will bring more energy and optimism to them. Sixth, the health and safety function of human resource management, in close coordination with the learning and development function, can create learning or informational content educating the individuals that being less optimistic can have adverse health consequences such as mental disorders and low life expectancy (Graham et al., 2020). Last, organizations and consultants may focus on the development of CDSE of employees because individuals' perceived ability to make decisions related to their career can boost up their morale to excel and progress towards their career goals with an optimistic frame of mind. To achieve the purpose, organizations and consultants may take support by introducing positive career shocks.

\subsection{Limitations and future research directions}

This study has certain limitations. First, the data were collected from employees working in the television channels of Pakistan. However, the electronic media in Pakistan includes radio stations and cable networks as well, other than the television channels. Thus, the results should be viewed and interpreted accordingly. Future studies may test the model for data collected from employees of radio stations and cable networks. Second, male representation was quite high $(69 \%)$ in our data; hence, a balanced representation may bring some interesting insights in future scholarships on the subject matter. Third, cross-sectional design is another limitation of examining the causal relationship. Future studies may retest the model of this study through longitudinal design. Fourth, the study takes three indicators of positive career shocks; however, future studies may increase the count of these indicators (see Sibert et al., 2013). Fifth, future studies may also integrate and control the demographic variables (e.g. gender, age) when examining career shocks and career optimism. Sixth, due to the COVID-19 pandemic organizations have switched to the work from home model and the majority of the workforce is facing employment and career challenges. This study received several responses to the questionnaire wherein potential respondents excused themselves due to bad health issues and the reason that they are no longer employed. Therefore, the study had a low response rate. Future studies should test the significance of our model with relatively a larger sample size in different careers and contexts. Last, latest studies on career optimism suggested adding more moderating variables in models studying career optimism such as personal resources (Hofer et al., 2020; Chui et al., 2020) and contextual resources (Hofer et al., 2020) etc. Future studies may test the personal resources, career resources and energy resources as moderating variables.

\section{Conclusion}

Principally, this study was aimed to examine the relationship of positive career shocks and career optimism. Additionally, the study was aimed to test the mediating role of CDSE on the relationship between positive career shocks and career optimism. Moderating role of CFC-I was tested between CDSE and career optimism. Data collected from the electronic media employees revealed that employees who receive positive career shocks are more likely to demonstrate high levels of CDSE, which in turn develops career optimism. The study further confirmed that interaction of CDSE and CFC-I strengthens the relationship of CDSE and career optimism. 


\section{References}

Adams, J. and Nettle, D. (2009), "Time perspective, personality and smoking, body mass, and physical activity: an empirical study", British Journal of Health Psychology, Vol. 14 No. 1, pp. 83-105.

Ahmad, B., Latif, S., Bilal, A.R. and Hai, M. (2019), "The mediating role of career resilience on the relationship between career competency and career success", Asia-Pacific Journal of Business Administration, Vol. 11 No. 3, pp. 209-231.

Akkermans, J., Seibert, S.E. and Mol, S.T. (2018), “Tales of the unexpected: integrating career shocks in the contemporary careers literature", SA Journal of Industrial Psychology, Vol. 44 No. 1, pp. 1-10.

Akkermans, J., Richardson, J. and Kraimer, M.L. (2020), "The Covid-19 crisis as a career shock: implications for careers and vocational behavior", Journal of Vocational Behavior, Vol. 119, 103434.

Alfalah, A.A. and Alganem, S.A. (2020), "The impact of construal level on happiness, hope, optimism, life satisfaction, and love of life: a longitudinal and experimental study", Australian Journal of Psychology, Vol. 72 No. 4, pp. 359-367.

Avkiran, N.K. (2017), "An in-depth discussion and illustration of partial least squares structural equation modeling in health care", Health Care Management Science, pp. 1-8.

Aymans, S.C., Kortsch, T. and Kauffeld, S. (2020), "Gender and career optimism-The effects of genderspecific perceptions of lecturer support, career barriers and self-efficacy on career optimism", Higher Education Quarterly, Vol. 74 No. 3, pp. 273-289.

Baruch, Y. and Lavi-Steiner, O. (2015), "The career impact of management education from an averageranked university", Career Development International, Vol. 20 No. 3, pp. 218-237.

Baruch, Y., Wordsworth, R., Mills, C. and Wright, S. (2016), "Career and work attitudes of blue-collar workers, and the impact of a natural disaster chance event on the relationships between intention to quit and actual quit behaviour", European Journal of Work and Organizational Psychology, Vol. 25 No. 3, pp. 459-473.

Betz, N.E., Klein, K.L. and Taylor, K.M. (1996), "Evaluation of a short form of the career decisionmaking self-efficacy scale", Journal of Career Assessment, Vol. 4 No. 1, pp. 47-57.

Biber, D.D., Melton, B. and Czech, D.R. (2020), "The impact of COVID-19 on college anxiety, optimism, gratitude, and course satisfaction", Journal of American College Health, pp. 1-6.

Blokker, R., Akkermans, J., Tims, M., Jansen, P. and Khapova, S. (2019), "Building a sustainable start: the role of career competencies, career success, and career shocks in young professionals' employability", Journal of Vocational Behavior, Vol. 112, pp. 172-184.

Chatterjee, S., Afshan, N. and Chhetri, P. (2015), "Exploring the linkage between the components of motivational systems theory and career decisiveness: the mediating role of career optimism”, Journal of Career Assessment, Vol. 23 No. 4, pp. 597-614.

Chen, S., Westman, M. and Eden, D. (2009), "Impact of enhanced resources on anticipatory stress and adjustment to new information technology: a field-experimental test of conservation of resources theory", Journal of Occupational Health Psychology, Vol. 14, pp. 219-230.

Chen, Q., Liang, M., Li, Y., Guo, J., Fei, D., Wang, L., He, L.I., Sheng, C., Cai, Y., Li, X. and Wang, J. (2020), "Mental health care for medical staff in China during the COVID-19 outbreak", The Lancet Psychiatry, Vol. 7 No. 4, pp. e15-e16.

Chin, W.W. (2010), "How to write up and report PLS analyses", in Esposito Vinzi, V., Chin, W.W., Henseler, J. and Wang, H. (Eds), Handbook of Partial Least Squares, Springer, Berlin, Heidelberg, pp. 655-690.

Chin, W.W., Gopal, A. and Salisbury, W.D. (1997), "Advancing the theory of adaptive structuration: the development of a scale to measure faithfulness of appropriation", Information Systems Research, Vol. 8, pp. 342-367.

Chui, H., Li, H. and Ngo, H.Y. (2020), "Linking protean career orientation with career optimism: career adaptability and career decision self-efficacy as mediators", Journal of Career Development. 
Chung, Y.B. (2002), "Career decision-making self-efficacy and career commitment: gender and ethnic differences among college students", Journal of Career Development, Vol. 28 No. 4, pp. 277-284.

Cohen, J. (1988), Statistical Power Analysis for the Behavioral Sciences, Lawrence Erlbaum Associates. Cooper, D. and Schindler, P. (2003), Business Research Methods, 8th ed., McGraw-Hill.

Creed, P.A., Patton, W. and Bartrum, D. (2002), "Multidimensional properties of the LOT-R: effects of optimism and pessimism on career and well-being related variables in adolescents", Journal of Career Assessment, Vol. 10 No. 1, pp. 42-61.

Dik, B.J., Sargent, A.M. and Steger, M.F. (2008), "Career development strivings: assessing goals and motivation in career decision-making and planning", Journal of Career Development, Vol. 35 No. 1, pp. 23-41.

Doo, M.Y. and Park, S.H. (2019), "Effects of work value orientation and academic major satisfaction on career decision-making self-efficacy", Higher Education, Skills and Work-Based Learning, Vol. 9 No. 4, pp. 550-562.

Eva, N., Newman, A., Jiang, Z. and Brouwer, M. (2020), "Career optimism: a systematic review and agenda for future research", Journal of Vocational Behavior, Vol. 116, 103287.

Fornell, C. and Larcker, D.F. (1981), "Evaluating structural equation models with unobservable variables and measurement errors", Journal of Marketing Research, Vol. 18 No. 1, pp. 39-50.

Fujita, K. and Sasota, J.A. (2011), "The effects of construal levels on asymmetric temptation-goal cognitive associations", Social Cognition, Vol. 29 No. 2, pp. 125-146.

Garcia, P.R.J.M., Restubog, S.L.D., Bordia, P., Bordia, S. and Roxas, R.E.O. (2015), “Career optimism: the roles of contextual support and career decision-making self-efficacy", Journal of Vocational Behavior, Vol. 88, pp. 10-18.

GCCI (2020), "Global consumer confidence Index 2020", available at: https://www.ipsos.com/sites/ default/files/ct/publication/documents/202003/ipsos_consumer_confidence_survey_in_ pakistan-december_2019-key_national_insights-16jan20.pdf.

Genç, E. and Arslan, G. (2021), 'Optimism and dispositional hope to promote college students' subjective well-being in the context of the COVID-19 pandemic", Journal of Positive School Psychology, Vol. 5 No. 2, pp. 87-96.

Graham, E.K., Weston, S.J., Turiano, N.A., Aschwanden, D., Booth, T., Harrison, F., James, B.D., Lewis, N.A., Makkar, S.R., Mueller, S. and Wisniewski, K.M. (2020), "Is healthy neuroticism associated with health behaviors? A coordinated integrative data analysis", Collabra: Psychology, Vol. 6 No. 1.

Graso, M. and Probst, T.M. (2012), "The effect of consideration of future consequences on quality and quantity aspects of job performance”, Journal of Applied Social Psychology, Vol. 42 No. 6, pp. 1335-1352.

Grimland, S., Vigoda-Gadot, E. and Baruch, Y. (2012), "Career attitudes and success of managers: the impact of chance event, protean, and traditional careers", The International Journal of Human Resource Management, Vol. 23 No. 6, pp. 1074-1094.

Guan, Y., Zhou, W., Ye, L., Jiang, P. and Zhou, Y. (2015), "Perceived organizational career management and career adaptability as predictors of success and turnover intention among Chinese employees", Journal of Vocational Behavior, Vol. 88, pp. 230-237.

Gunkel, M. and Schlaegel, C. (2010), "The influence of personality on students' career decisiveness-a comparison between Chinese and German economics and management students", Management Revue, pp. 229-243.

Gunkel, M., Schlägel, C., Langella, I.M., Peluchette, J.V. and Reshetnyak, E. (2013), "The influence of national culture on business students' career attitudes-an analysis of eight countries", German Journal of Human Resource Management, Vol. 27 No. 1, pp. 47-68.

Hai, M., Latif, S., Bilal, A.R. and Ahmad, B. (2020), "Respect: give it to get it! Does leadership complimented with respect can foster creativity?", International Journal of Emerging Markets.
Positive career shocks and career optimism 
Hair, F.J. Jr, Sarstedt, M., Hopkins, L. and Kuppelwieser, G.V. (2014), "Partial least squares structural equation modeling (PLS-SEM) an emerging tool in business research", European Business Review, Vol. 26 No. 2, pp. 106-121.

Hair, J.F., Henseler, J., Dijkstra, T.K. and Sarstedt, M. (2014), Common Beliefs and Reality about Partial Least Squares: Comments on Rönkkö and Evermann.

Hair, J.F., Halt, G.T.M., Ringle, C.M. and Sarstedt, M. (2017), A Primer on Partial Least Squares Structural Equation Modeling (PLS-SEM), 2nd ed., Sage, Thousand Oaks, California, CA.

Halbesleben, J.R., Neveu, J.P., Paustian-Underdahl, S.C. and Westman, M. (2014), "Getting to the "COR" understanding the role of resources in conservation of resources theory", Journal of Management, Vol. 40 No. 5, pp. 1334-1364.

Hall, D.T. (2002), Careers in and Out of Organizations, Sage, Thousand Oaks, California, CA.

Harman, H.H. (1967), Modern Factor Analysis, University of Chicago Press, Chicago, Illinois, IL.

Hayes, A.F. and Rockwood, N.J. (2016), "Regression-based mediation and moderation analysis in clinical research: observations, recommendations, and implementation”, Behaviour Research and Therapy, Vol. 98, pp. 39-57.

Heerwegh, D. (2009), "Mode differences between face-to-face and web surveys: an experimental investigation of data quality and social desirability effects", International Journal of Public Opinion Research, Vol. 21 No. 1, pp. 111-121.

Henseler, J. (2010), "On the convergence of the partial least squares path modeling algorithm", Computational Statistics, Vol. 25 No. 1, pp. 107-120.

Henseler, J., Dijkstra, T.K., Sarstedt, M., Ringle, C.M., Diamantopoulos, A., Straub, D.W., Ketchen, D.J. Jr, Hair, J.F., Hult, G.T.M. and Calantone, R.J. (2014), "Common beliefs and reality about PLS: comments on Rönkkö and Evermann (2013)", Organizational Research Methods, Vol. 17 No. 2, pp. 182-209.

Henseler, J., Ringle, C.M. and Sarstedt, M. (2015), “A new criterion for assessing discriminant validity in variance-based structural equation modelling", Journal of the Academy of Marketing Science, Vol. 43 No. 1, pp. 115-135.

Hernández-Sánchez, B.R., Cardella, G.M. and Sánchez-García, J.C. (2020), "Psychological factors that lessen the impact of COVID-19 on the self-employment intention of business administration and economics' students from Latin America", International Journal of Environmental Research and Public Health, Vol. 17 No. 15, p. 5293.

Ho, E.S.C. and Sum, K.W. (2018), "Construction and validation of the career and educational decision self-efficacy inventory for secondary students (CEDSIS)", Journal of Psychoeducational Assessment, Vol. 36 No. 2, pp. 162-174.

Hobfoll, S.E. (1989), "Conservation of resources: a new attempt at conceptualizing stress", American Psychologist, Vol. 44 No. 3.

Hobfoll, S.E. (2001), "The influence of culture, community, and the nested-self in the stress process: advancing conservation of resources theory", Applied Psychology, Vol. 50 No. 3, pp. 337-421.

Hobfoll, S.E. (2011), "Conservation of resource caravans and engaged settings", Journal of Occupational and Organizational Psychology, Vol. 84 No. 1, pp. 116-122.

Hobfoll, S.E., Halbesleben, J., Neveu, J.P. and Westman, M. (2018), "Conservation of resources in the organizational context: the reality of resources and their consequences", Annual Review of Organizational Psychology and Organizational Behavior, Vol. 5, pp. 103-128.

Hofer, A., Spurk, D. and Hirschi, A. (2020), "When and why do negative organization-related career shocks impair career optimism? A conditional indirect effect model", Career Development International.

Hu, L.T. and Bentler, P.M. (1999), "Cutoff criteria for fit indexes in covariance structure analysis: conventional criteria versus new alternatives", Structural Equation Modeling: A Multidisciplinary Journal, Vol. 6 No. 1, pp. 1-55. 
ILO (2020), "How will COVID-19 affect the world of work?”, available at: https://www.ilo.org/global/ topics/coronavirus/impacts-and-responses/WCMS_739047/lang-en/index.htm (accessed 05 May 2021).

Joireman, J., Kamdar, D., Daniels, D. and Duell, B. (2006), "Good citizens to the end? It depends: empathy and concern with future consequences moderate the impact of a short-term time horizon on organizational citizenship behaviors", Journal of Applied Psychology, Vol. 91 No. 6, pp. 1307-1320.

Joireman, J., Shaffer, M.J., Balliet, D. and Strathman, A. (2012), "Promotion orientation explains why future-oriented people exercise and eat healthy: evidence from the two-factor consideration of future consequences-14 scale", Personality and Social Psychology Bulletin, Vol. 38 No. 10, pp. 1272-1287.

Kim, J., Kim, P.B., Kim, J.E. and Magnini, V.P. (2016), "Application of construal-level theory to promotional strategies in the hotel industry", Journal of Travel Research, Vol. 55 No. 3, pp. 340-352.

Lent, R.W., Brown, S.D. and Hackett, G. (1994), "Toward a unifying social cognitive theory of career and academic interest, choice, and performance", Journal of Vocational Behavior, Vol. 45 No. 1, pp. 79-122.

Lewis, E.F., Hardy, M. and Snaith, B. (2013), "An analysis of survey reporting in the imaging professions: is the issue of non-response bias being adequately addressed?", Radiography, Vol. 19 No. 3, pp. 240-245.

Li, H., Ngo, H.Y. and Cheung, F. (2019), "Linking protean career orientation and career decidedness: the mediating role of career decision self-efficacy", Journal of Vocational Behavior, Vol. 115, 103322.

Liberman, N. and Trope, Y. (1998), "The role of feasibility and desirability considerations in near and distant future decisions: a test of temporal construal theory", Journal of Personality and Social Psychology, Vol. 75 No. 1.

Little, R.J. (1988), "A test of missing completely at random for multivariate data with missing values", Journal of the American Statistical Association, Vol. 83 No. 404, pp. 1198-1202.

Little, T.D., Cunningham, W.A., Shahar, G. and Widaman, K.F. (2002), "To parcel or not to parcel exploring the question, weighing the merits", Structural Equation Modeling, Vol. 9 No. 2, pp. 151-173.

Lohmöller, J.B. (1989), Latent Variable Path Modeling with Partial Least Squares, Physica, Heidelberg. Maddux, J.E. (2002), “The power of believing you can”, Handbook of Positive Psychology, pp. 277-287.

Matsunaga, M. (2008), "Item parceling in structural equation modeling: a primer", Communication Methods and Measures, Vol. 2 No. 4, pp. 260-293.

McLennan, B., Mcllveen, P. and Perera, H.N. (2017), "Pre-service teachers' self-efficacy mediates the relationship between career adaptability and career optimism", Teaching and Teacher Education, Vol. 63, pp. 176-185.

Memon, M.A., Sallaeh, R., Baharom, M.N.R., Md Nordin, S. and Ting, H. (2017), "The relationship between training satisfaction, organisational citizenship behaviour, and turnover intention: a PLS-SEM approach", Journal of Organizational Effectiveness: People and Performance, Vol. 4 No. 3, pp. 267-290.

Murphy, L., Cadogan, E. and Dockray, S. (2020), "The consideration of future consequences: evidence for domain specificity across five life domains", Personality and Social Psychology Bulletin, Vol. 46 No. 5 , pp. $663-678$.

$\mathrm{Niu}, \mathrm{H} . J$. (2010), "Investigating the effects of self-efficacy on foodservice industry employees' career commitment", International Journal of Hospitality Management, Vol. 29, pp. 743-750.

Orbell, S. and Kyriakaki, M. (2008), "Temporal framing and persuasion to adopt preventive health behavior: moderating effects of individual differences in consideration of future consequences on sunscreen use", Health Psychology, Vol. 27 No. 6, pp. 770-779.
Positive career shocks and career optimism

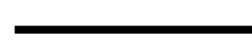


Pahi, M.H., Ahmed, U., Sheikh, A.Z., Dakhan, S.A., Khuwaja, F.M. and Ramayah, T. (2020), "Leadership and commitment to service quality in Pakistani hospitals: the contingent role of role clarity", SAGE Open, Vol. 10 No. 4, pp. 2-14.

Park, J. and Yang, J.S. (2019), "Moderating effects of the timing of reward determination and performance standards between rewards and self-efficacy for sustainable intrinsic motivation”, Sustainability, Vol. 11 No. 17, p. 4619.

Penn, L.T. and Lent, R.W. (2019), "The joint roles of career decision self-efficacy and personality traits in the prediction of career decidedness and decisional difficulty", Journal of Career Assessment, Vol. 27 No. 3, pp. 457-470.

Reio, T.G. Jr (2010), "The threat of common method variance bias to theory building", Human Resource Development Review, Vol. 9 No. 4, pp. 405-411.

Rezaei, S. and Ghodsi, S.S. (2014), "Does value matters in playing online game? An empirical study among massively multiplayer online role-playing games (MMORPGs)", Computers in Human Behavior, Vol. 35, pp. 252-266.

Rezaei, S., Ali, F., Amin, M. and Jayashree, S. (2016), "Online impulse buying of tourism products: the role of web site personality, utilitarian and hedonic web browsing", Journal of Hospitality and Tourism Technology, Vol. 7 No. 1, pp. 60-83.

Richter, A.W., Hirst, G., Van Knippenberg, D. and Baer, M. (2012), "Creative self-efficacy and individual creativity in team contexts: cross-level interactions with team informational resources”, Journal of Applied Psychology, Vol. 97 No. 6, pp. 1282-1290.

Ringle, C.M., Wende, S. and Becker, J.M. (2015), "SmartPLS 3. Bönningstedt: SmartPLS”, available at: http://www.smartpls.com.

Rogers, M.E. and Creed, P.A. (2011), "A longitudinal examination of adolescent career planning and exploration using a social cognitive career theory framework", Journal of Adolescence, Vol. 34 No. 1, pp. 163-172.

Roldan, J.L. and Sanchez -Franco, M.J. (2012), "Variance -based structural equation modeling: guidelines for using partial least squares in information systems research", Research Methodologies, Innovations and Philosophies in Software Systems Engineering and Information Systems, IGI Global, pp. 193-221.

Roni, M.S. (2014), Introduction to SPSS, Edith Cowan University.

Rottinghaus, P.J., Day, S.X. and Borgen, F.H. (2005), "The Career Futures Inventory: a measure of career-related adaptability and optimism”, Journal of Career Assessment, Vol. 13 No. 1, pp. 3-24.

Rubel, M.R.B., Kee, D.M.H. and Rimi, N.N. (2021), "The influence of green HRM practices on green service behaviors: the mediating effect of green knowledge sharing", Employee Relations: The International Journal.

Rubin, D. (1987), Multiple Imputation for Nonresponse in Surveys, John Wiley \& Sons.

Rucker, D.D., Preacher, K.J., Tormala, Z.L. and Petty, R.E. (2011), "Mediation analysis in social psychology: current practices and new recommendations", Social and Personality Psychology Compass, Vol. 5 No. 6, pp. 359-371.

Saunders, M.N.K., Lewis, P. and Thornhill, A. (2016), Research Methods for Business Students, Pearson, Harlow.

Schafer, J.L. and Olsen, M.K. (1998), "Multiple imputation for multivariate missing-data problems: a data analyst's perspective”, Multivariate Behavioral Research, Vol. 33 No. 4, pp. 545-571.

Schwarz, A., Rizzuto, T., Carraher-Wolverton, C., Roldan, J.L. and Barrera-Barrera, R. (2017), "Examining the impact and detection of the urban legend of common method bias", ACMSIGMIS - Data Base: The DATABASE for Advances in Information Systems, Vol. 48 No. 1, pp. 93-119.

Seibert, S.E., Kraimer, M.L., Holtom, B.C. and Pierotti, A.J. (2013), "Even the best laid plans sometimes go askew: career self-management processes, career shocks, and the decision to pursue graduate education”, Journal of Applied Psychology, Vol. 98 No. 1, pp. 169-182. 
Shin, J., Taylor, M.S. and Seo, M.G. (2012), "Resources for change: the relationships of organizational inducements and psychological resilience to employees' attitudes and behaviors toward organizational change", Academy of Management Journal, Vol. 55 No. 3, pp. 727-748.

Strathman, A., Gleicher, F., Boninger, D.S. and Edwards, C.S. (1994), "The consideration of future consequences: weighing immediate and distant outcomes of behavior", Journal of Personality and Social Psychology, Vol. 66 No. 4, pp. 742-752.

Taylor, K.M. and Betz, N.E. (1983), "Applications of self-efficacy theory to the understanding and treatment of career indecision”, Journal of Vocational Behavior, Vol. 22 No. 1, pp. 63-81.

Ten Brummelhuis, L.L. and Bakker, A.B. (2012), "A resource perspective on the work-home interface: the work-home resources model”, American Psychologist, Vol. 67 No. 7, pp. 545-556.

Trope, Y. and Liberman, N. (2010), "Construal-level theory of psychological distance", Psychological Review, Vol. 117 No. 2.

Urbig, D. and Monsen, E. (2012), "The structure of optimism: controllability affects the extent to which efficacy beliefs shape outcome expectancies", Journal of Economic Psychology, Vol. 33 No. 4, pp. 854-867.

Uttley, J. (2019), "Power analysis, sample size, and assessment of statistical assumptions-Improving the evidential value of lighting research", Leukos, Vol. 15 Nos 2-3, pp. 143-162.

Wang, C.J. and Tseng, K.J. (2019), "Effects of selected positive resources on hospitality service quality: the mediating role of work engagement", Sustainability, Vol. 11.

Ylldırım, M., Çiçek, İ. and Şanll, M.E. (2021), "Coronavirus stress and COVID-19 burnout among healthcare staffs: the mediating role of optimism and social connectedness", Current Psychology, pp. 1-9.

Young, D.K., Carpenter, D. and Maasberg, M. (2018), "An examination of factors that influence students' IT career decisions", Journal of Computer Information Systems, Vol. 58 No. 3, pp. 253-263.

\section{Corresponding author}

Bilal Ahmad can be contacted at: azrabilalbashir@yahoo.com

For instructions on how to order reprints of this article, please visit our website:

www.emeraldgrouppublishing.com/licensing/reprints.htm

Or contact us for further details: permissions@emeraldinsight.com 